\title{
Le sourire d'Albert Camus, sous la direction de David H. WALKER
}

\section{Monia Mezzetti}

\section{OpenEdition}

\section{Journals}

\section{Edizione digitale}

URL: http://journals.openedition.org/studifrancesi/16690

DOI: 10.4000/studifrancesi. 16690

ISSN: 2421-5856

\section{Editore}

Rosenberg \& Sellier

\section{Edizione cartacea}

Data di pubblicazione: 1 juillet 2019

Paginazione: 190

ISSN: 0039-2944

\section{Notizia bibliografica digitale}

Monia Mezzetti, «Le sourire d'Albert Camus, sous la direction de David H. waLkeR», Studi Francesi [Online], 187 (LXIII | I) | 2019, online dal 01 juillet 2019, consultato il 25 janvier 2021. URL: http://

journals.openedition.org/studifrancesi/16690 ; DOI: https://doi.org/10.4000/studifrancesi.16690

Questo documento è stato generato automaticamente il 25 janvier 2021.

\section{(a) $\odot \Theta$}

Studi Francesi è distribuita con Licenza Creative Commons Attribuzione - Non commerciale - Non opere derivate 4.0 Internazionale. 


\title{
Le sourire d'Albert Camus, sous la direction de David H. WALKER
}

\author{
Monia Mezzetti
}

\section{NOTIZIA}

Le sourire d'Albert Camus, sous la direction de David H. WALKER, CreateSpace Independent Publishing, 2018, 279 pp.

1 Il volume raccoglie gli Atti del convegno tenutosi a Aix-en-Provence nel 2017 presso l'Institut Américain Universitaire sotto l'egida della Société des Études Camusiennes, il cui obiettivo era quello di rimediare a una sorta di lacuna nell'ermeneutica dell'opera dello scrittore, ovvero la mancata considerazione della vena umoristica. Lo spunto è offerto dalle dichiarazioni del romanziere stesso, il quale, nel 1959, in un'intervista, ebbe a servirsi proprio della parola humour (p. 8) per designare il tema a suo giudizio sino ad allora trascurato dalla critica. Dal canto loro, i promotori del convegno si riferiscono a questo ambito di ricerca con il termine di sourire per le implicazioni eticoaffettive e le peculiarità fisiognomiche proprie di questa espressione del volto umano, le quali, come emerge nelle pagine introduttive, in mancanza di un studio specifico, possono essere desunte per antitesi dal confronto con quelle individuate da Bergson riguardo al riso (Essai sur la signification du comique, 1900). Pertanto, allorché quest'ultimo, secondo il filosofo, è «incompatible avec l'émotion» e «n'aurait ... rien de très bienveillant» (pp. 8-9) poiché reca con sé «l'intention inavouée d'humilier», il sorriso si colloca invece nella dimensione dell'empatia in base a un preliminare riconoscimento dell'altro come un possibile sé; ne discende quindi un atteggiamento di complicità, di simpatia in senso etimologico, che fa astenere dal prorompere in una manifestazione incontrollata di ilarità. Inoltre, sotto il profilo fisiognomico, mentre il riso, sempre secondo Bergson, «est un geste qui fait légèrement peur» (p. 9) per via delle implicazioni archetipiche dell'inevitabile messa in mostra della dentatura, il sorriso la cela con discrezione, in quanto esso stesso esito di una mimica più complessa. 
Rispetto a questa tassonomia i contributi degli autori risultano tutti coerenti, mentre lo sono meno rispetto alle sezioni in cui il volume è suddiviso; il raggruppamento segue infatti criteri a volte non sufficientemente chiari. L'ermeneutica dell'oggetto di studio del convegno compare infatti in quattro articoli appartenenti ad altrettante sezioni: in quello di S. GESKE (sezione 5, «Rire ou sourire: comédie ou tragédie?»), dedicato all'umorismo in L'envers et l'endroit e al Mythe de Sisyphe, dove esso risulta funzionale a «désamorcer le désespoir» (p. 209), ma anche in quello a firma di G. GAETANI (sez. 4, «Philosophie, politique, journalisme»), relativo al ruolo dell'ironia come modalità per accostarsi agli eventi nell'Impromptu des philosophes, e ancora nel saggio di I. CASSAGNE (sez. 2, «Le monde, le moi et les autres»), dove il tema del sorriso viene interpretato, in modo originale, come atteggiamento, «démonstration d'accueil "souriante"» (p. 109), ossia di apertura, disponibilità di Camus nei confronti dei suoi interlocutori, nel caso specifico Ponge, Louis Gouilloux e soprattutto Char. Di particolare interesse risultano gli articoli che passano in rassegna le occorrenze del tema del sorriso tanto nei saggi (ZAULI, GAETANI) quanto nell'opera narrativa (ZAULI, MANAY-ZAYAR), teatrale (RIFAT, LUPO) e poetica (SPIQUEL, sul componimento giovanile Méditerranée, dove emerge una concezione panteista: «sourire de la mer», «sourire du monde», «sourire du ciel»). Altri contributi vertono infine su un ventaglio eterogeneo di aspetti: dall'interesse di Camus per il sorriso dei kouroi greci (WALKER), alla riproposizione in chiave ludica del francese parlato in Algeria (BASSET, REY), al ruolo dell'ironia negli articoli giornalistici del 1938-1940 (BRÉJON) e nei Cahiers (DERELLE e BAUDOUï), al ricorso a una comicità palesemente tributaria di Ionesco (RODAN, il cui articolo risulta però non ben calibrato, perché principalmente incentrato sul tema della Cecoslovacchia nelle opere giovanili, a sua volta riconducibile alle reminiscenze di un viaggio compiuto dallo scrittore nell'agosto del 1936). Corredano il volume un contributo non firmato a scopo documentativo sul ruolo dell'umorismo nella pubblicità su carta stampata ai tempi di Camus (pp. 273-276) e un breve saggio «en guise de pastiche» (p. 279) di Guy BASSET sull'importanza della levità nell'opera dell'A. (pp. 278-279). 